\title{
Cyclic ADP-ribose and NAADP: fraternal twin messengers for calcium signaling
}

\author{
Hon Cheung LEE \\ Department of Physiology, University of Hong Kong, Hong Kong, China \\ Received May 11, 2011; accepted June 10, 2011
}

\begin{abstract}
The concept advanced by Berridge and colleagues that intracellular $\mathrm{Ca}^{2+}$-stores can be mobilized in an agonist-dependent and messenger $\left(\mathrm{IP}_{3}\right)$-mediated manner has put $\mathrm{Ca}^{2+}$-mobilization at the center stage of signal transduction mechanisms. During the late 1980s, we showed that $\mathrm{Ca}^{2+}$-stores can be mobilized by two other messengers unrelated to inositol trisphosphate $\left(\mathrm{IP}_{3}\right)$ and identified them as cyclic ADP-ribose (cADPR), a novel cyclic nucleotide from NAD, and nicotinic acid adenine dinucleotide phosphate (NAADP), a linear metabolite of NADP. Their messenger functions have now been documented in a wide range of systems spanning three biological kingdoms. Accumulated evidence indicates that the target of cADPR is the ryanodine receptor in the sarco/endoplasmic reticulum, while that of NAADP is the two pore channel in endolysosomes.

As cADPR and NAADP are structurally and functionally distinct, it is remarkable that they are synthesized by the same enzyme. They are thus fraternal twin messengers. We first identified the Aplysia ADP-ribosyl cyclase as one such enzyme and, through homology, found its mammalian homolog, CD38. Gene knockout in mice confirms the important roles of CD38 in diverse physiological functions from insulin secretion, susceptibility to bacterial infection, to social behavior of mice through modulating neuronal oxytocin secretion. We have elucidated the catalytic mechanisms of the Aplysia cyclase and CD38 to atomic resolution by crystallography and site-directed mutagenesis. This article gives a historical account of the cADPR/NAADP/CD38-signaling pathway and describes current efforts in elucidating the structure and function of its components.
\end{abstract}

cyclic ADP-ribose, cADPR, NAADP, nicotinic acid adenine dinucleotide phosphate, CD38, ADP-ribosyl cyclase, Calcium mobilization and signaling

Citation: $\quad$ Lee H C. Cyclic ADP-ribose and NAADP: fraternal twin messengers for calcium signaling. Sci China Life Sci, 2011, 54: 699-711, doi: $10.1007 / \mathrm{s} 11427-011-4197-3$

In 1983, Berridge and colleagues published a study showing that agonists, such as carbachol, can activate $\mathrm{Ca}^{2+}$ release from non-mitochondrial $\mathrm{Ca}^{2+}$ stores and the effect is mediated by a $\mathrm{Ca}^{2+}$ messenger, inositol 1,4,5-trisphosphate $\left(\mathrm{IP}_{3}\right)$ [1]. The targeted $\mathrm{Ca}^{2+}$ stores were later identified as the endoplasmic reticulum (ER), which has since been shown to be the major intracellular $\mathrm{Ca}^{2+}$ stores. This seminal study ushered in the current field of $\mathrm{Ca}^{2+}$ signaling as we know it and has made the field center stage. $\mathrm{IP}_{3}$ is derived from a phospholipid, phosphatidyl inositol 4,5-bisphosphate,

email: leehc@hku.hk present on the cytoplasmic side of the plasma membrane. Agonist binding to its specific receptor leads to activation of phospholipase $\mathrm{C}$ and the hydrolysis of the phospholipid, releasing the head group that is $\mathrm{IP}_{3}$. The structure of $\mathrm{IP}_{3}$ is shown in Figure 1. It has three phosphates on the inositol ring. Both the number of phosphates and the position of the phosphates are critical to the binding of $\mathrm{IP}_{3}$ to its receptor in the ER. The space-filling model of $\mathrm{IP}_{3}$ shown in Figure 1 is based on the crystal coordinates of $\mathrm{IP}_{3}$ bound to its receptor [2].

With the $\mathrm{IP}_{3}$-pathway elucidated, two obvious questions follow; namely, whether there are other $\mathrm{Ca}^{2+}$ signaling- 

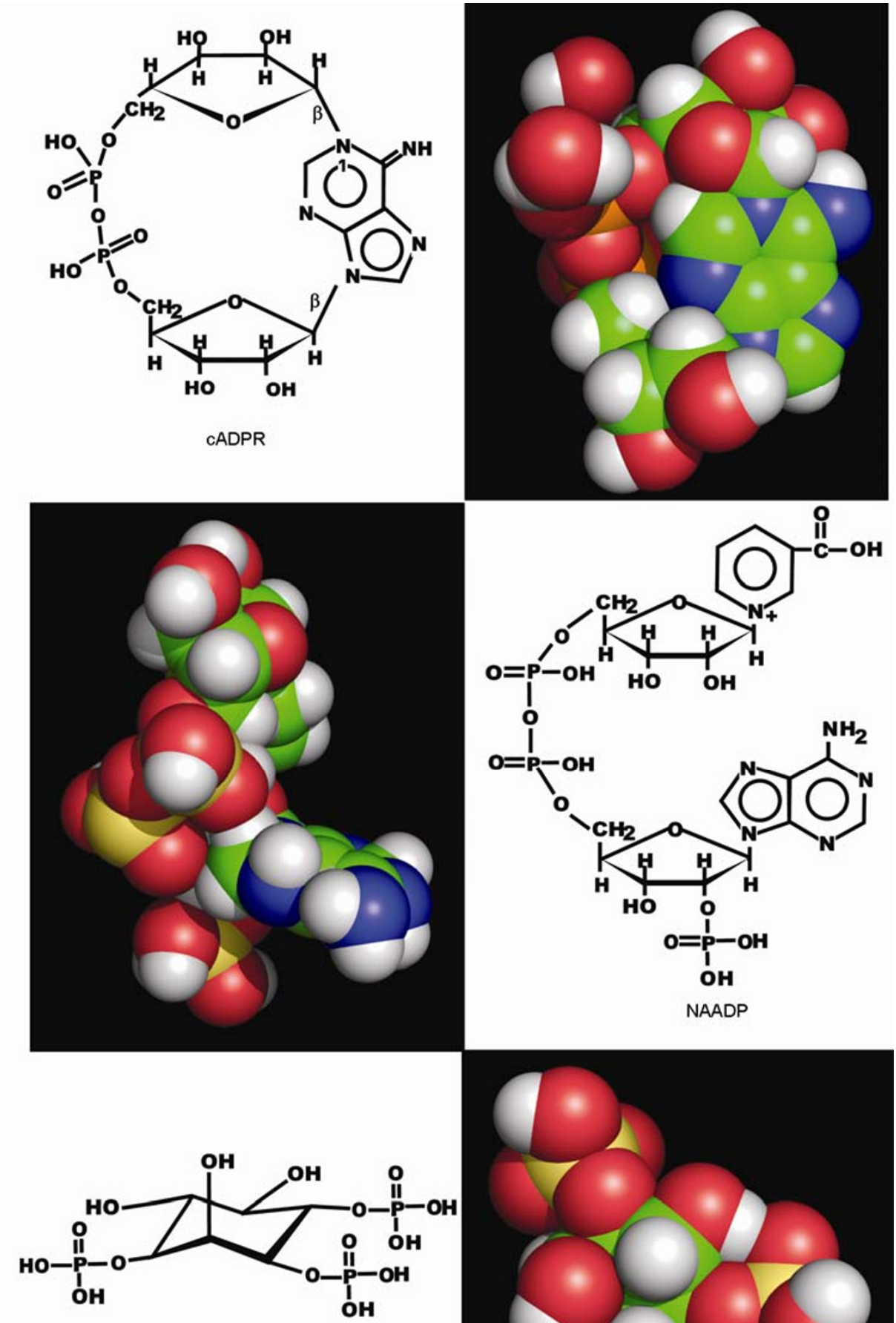

$\mathrm{IP}_{3}$

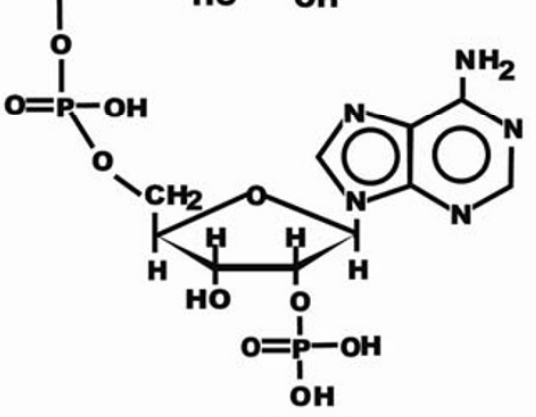

NAADP

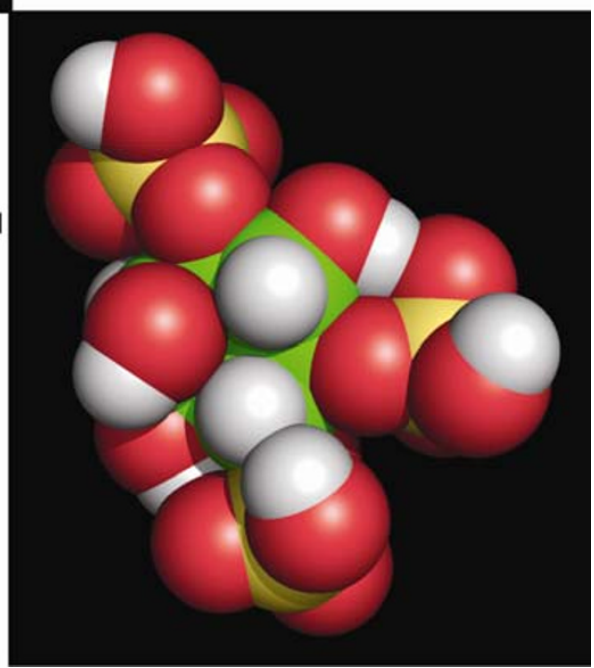

Figure 1 Structures of messenger molecules for $\mathrm{Ca}^{2+}$ signaling. The space-filling models of cyclic ADP-ribose (cADPR), nicotinic acid adenine dinucleotide phosphate (NAADP) and inositol 1,4,5-trisphosphate $\left(\mathrm{IP}_{3}\right)$ are based on crystal structures. The color coding is carbon: green, nitrogen: blue, oxygen: red, hydrogen: white, phosphorus: yellow. 
pathways present in cells and whether there are $\mathrm{Ca}^{2+}$ stores other than the ER. The answers to both questions are affirmative and are the focus of this article. As will be described below, the other $\mathrm{Ca}^{2+}$ signaling pathways are mediated by two novel $\mathrm{Ca}^{2+}$ mobilizing messengers, cyclic ADP-ribose (cADPR) and nicotinic acid adenine dinucleotide phosphate (NAADP). Neither their structures nor the substrates they derive from have any similarity with those of $\mathrm{IP}_{3}$, however. Both these new messengers are nucleotides. Cyclic ADP-ribose is derived from NAD, while NAADP is from NADP. The $\mathrm{Ca}^{2+}$ stores they target are also different; cADPR acts on the ER, similar to $\mathrm{IP}_{3}$, but NAADP targets the lysosome-like acidic stores. Nevertheless, both these nucleotide messengers are synthesized by the same multi-functional signaling enzyme, CD38. They are thus fraternal twin messengers for $\mathrm{Ca}^{2+}$ signaling.

\section{Discovery of cADPR and NAADP}

The discovery of the nucleotide messengers was made in the late 1980s [3,4], a few years after the elucidation of the $\mathrm{IP}_{3}$-pathway. The strategy devised was to isolate the endoplasmic $\mathrm{Ca}^{2+}$ stores and use them as an in vitro assay for $\mathrm{Ca}^{2+}$ release activators [5]. The cell selected was sea urchin egg because it has an abundant and elaborate ER system, and had been a well studied system for the release of internal $\mathrm{Ca}^{2+}$ on fertilization [6]. The endoplasmic preparations made from the eggs are remarkably stable and responded well to $\mathrm{IP}_{3}$ as expected. What was unanticipated was that both NAD and NADP were equally effective in releasing $\mathrm{Ca}^{2+}$ from the preparations [3]. Both NAD and NADP are coenzymes of oxidative reactions in cells and neither had ever been suspected to be involved in $\mathrm{Ca}^{2+}$ signaling. The $\mathrm{Ca}^{2+}$ release induced by NAD showed a characteristic delay distinctly different from the immediate release induced by $\mathrm{IP}_{3}$, as can be seen from Figure 2. This was shown to be due to enzymatic conversion of NAD to an active metabolite that was later identified as cADPR, a novel cyclic nucleotide hitherto unknown [4,7]. Its structure is shown in Figure 1. During the enzymatic conversion, the nicotinamide group of NAD is cleaved and the N1 of the adenine is linked back to the terminal ribose, forming a head to tail circle. The space-filling model in the figure is rendered using the crystal coordinates of cADPR [7]. Based on the structure, a total chemical synthesis of cADPR, a tour de force, has been achieved [8] and a large number of analogs have since been produced (reviewed in [9]). That cADPR is in fact a natural metabolite endogenously present in tissues was first shown in rats, using sea urchin egg microsomes as a bioassay for cADPR (Figure 2) [10].

Unlike NAD, NADP induced $\mathrm{Ca}^{2+}$ release without a delay as shown in Figure 2. The release was not, however, due to NADP, but a minute contaminant in the commercial preparations of NADP that was later identified as

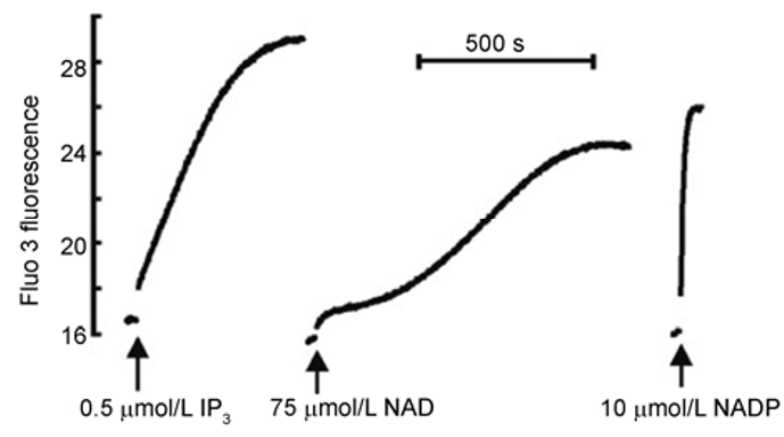

Figure 2 Discovery of cADPR and NAADP. The ability of NAD(P) to release $\mathrm{Ca}^{2+}$ was first demonstrated using microsomes isolated from sea urchin eggs. The release of $\mathrm{Ca}^{2+}$ was detected by the $\mathrm{Ca}^{2+}$ indicator, Fluo 3 , as increase in fluorescence. The amounts of $\mathrm{Ca}^{2+}$ release were comparable with that released by $\mathrm{IP}_{3}$, a known $\mathrm{Ca}^{2+}$ mobilizing messenger. The initial delay in $\mathrm{Ca}^{2+}$ release induced by NAD was shown to be due to its enzymatic conversion to cADPR, while the response to NADP was due to a contaminant in NADP that was later identified as NAADP.

NAADP [11]. It is a derivative of NADP and the only structural change is the conversion of the amide group of the nicotinamide in NADP to a carboxyl group. It is a linear molecule like NADP, and not a cyclic nucleotide like cADPR. As will be described later, NAADP is a natural metabolite of NADP. Remarkably, even though cADPR and NAADP are derived from different substrates with totally distinct structures and they target separate $\mathrm{Ca}^{2+}$ stores (see below), both are synthesized by the same enzyme, CD38. We have recently obtained the crystal coordinates of NAADP bound to CD38 (unpublished data by Zhang, Lee and Hao), which definitively confirm the chemical structure of NAADP shown in Figure 1.

\section{2 cADPR and NAADP are second messengers}

Since the discovery in sea urchin eggs, cADPR and NAADP have been shown to be active in mobilizing $\mathrm{Ca}^{2+}$ in a wide range of cells spanning three biological kingdoms, from protozoa [12], plant $[13,14]$ to animal, including human $[15,16]$ (reviewed in [17]).

That cADPR serves as a second messenger for $\mathrm{Ca}^{2+}$ mobilization has been documented in many cell systems, including sea urchin eggs. Thus, fertilization activates cADPR synthesis, which temporally correlates with the occurrence of the $\mathrm{Ca}^{2+}$ wave $[18,19]$. Injection of cADPR into the eggs elicits a similar $\mathrm{Ca}^{2+}$ increase, formation of the fertilization membrane and activation of DNA synthesis [20]. Inhibition of the $\mathrm{Ca}^{2+}$-release mechanism of cADPR, likewise, alters the characteristic of the $\mathrm{Ca}^{2+}$ wave at fertilization $[19,21,22]$.

Similar evidence shows that NAADP is also a second messenger (reviewed in [23,24]). For example, in pancreatic acinar cells (reviewed in [25]), the first mammalian cell shown to be responsive to NAADP, physiological concen- 
trations of cholecystokinin (CCK) activate $\mathrm{Ca}^{2+}$ changes that can be blocked by desensitizing the NAADP-mechanism [26]. Introduction of NAADP into the cells induces similar $\mathrm{Ca}^{2+}$ changes. Both the endogenous NAADP and cADPR levels are rapidly elevated by CCK, with NAADP preceding that of cADPR [27]. This has led to the proposal that NAADP may function as a $\mathrm{Ca}^{2+}$ trigger, whose signal is then amplified by the cADPR and $\mathrm{IP}_{3}$-pathways $[26,28]$.

Similar messenger functions of NAADP have also been shown in pancreatic beta cells (reviewed in [29]). Thus, treatment with glucose induces $\mathrm{Ca}^{2+}$ changes and increases the endogenous NAADP levels [30]. Experimental elevation of NAADP in the cells activates similar $\mathrm{Ca}^{2+}$ changes, while desensitizing the NAADP-mechanism blocks the glucose-induced $\mathrm{Ca}^{2+}$ changes [30,31].

\section{3 cADPR targets the ryanodine receptors in ER}

That cADPR is targeting a $\mathrm{Ca}^{2+}$ release mechanism different from that of $\mathrm{IP}_{3}$ was clearly indicated by the differences in pharmacology $[3,20]$. Another major $\mathrm{Ca}^{2+}$ release mechanism in the ER known even before the discovery of the $\mathrm{IP}_{3}$-pathway is the $\mathrm{Ca}^{2+}$-induced $\mathrm{Ca}^{2+}$ release (CICR) mechanism mediated by the ryanodine receptor (RyR). This mechanism is responsible for regulating muscle contraction in cardiac myocytes. The pharmacology of the CICR mechanism is very similar to that of the cADPR-mechanism [32]. Indeed, nanomolar concentrations of cADPR can greatly increase the sensitivity of the CICR mechanism to $\mathrm{Ca}^{2+}$ $[32,33]$. The activity of the isolated RyR incorporated into lipid bilayers is stimulated by cADPR and so is the binding of ryanodine to cardiac sarcroplasmic microsomes, particularly at low $\mathrm{Ca}^{2+}$ conditions [34]. Several subsequent studies report negative results [35-37]. A series of more recent articles from independent groups, however, convincingly confirms the original observations using the reconstituted RyR [38-40]. Moreover, in cardiac myocytes, cADPR is shown to increase the frequency of $\mathrm{Ca}^{2+}$ sparks, a manifestation of local opening of the RyR channels [41-44]. Most recently, HEK293 cells are shown to be responsive to cADPR if and only if they are expressing RyR [45].

The discrepancy between these recent studies and the earlier negative results could be attributed to the requirement of associate protein factors for the action of cADPR on RyR. These factors include calmodulin [46-50] and FK506 Binding Protein [40,43,44,51-53]. Care must thus be exercised to prevent disruption of the association of these factors with the RyR.

\section{4 cADPR can activate $\mathrm{Ca}^{2+}$-influx}

Paradoxically, cADPR can also activate $\mathrm{Ca}^{2+}$ influx in some cell types, including lymphocytes [54], neutrophils [55] and pancreatic $\beta$-cells [56]. An increasing number of studies indicate that the $\mathrm{Ca}^{2+}$ influx occurs via the stimulation of the TRPM2 channel in the plasma membrane. Accordingly, when TRPM2 is transfected and expressed in HEK293 cells, delivery of cADPR into the cells via patch-clamping activates the TRPM2 current [56-58]. Similar activation of the TRPM2 channel is seen in primary cells, such as neutrophils [55] and pancreatic $\beta$-cells [56].

TRPM2 is a member of the M-family of transient receptor potential channels (reviewed in [59]). These channels are widely expressed in many tissues and are best recognized for their contributions to sensory transduction, including response to temperature. The first identified activating ligand for TRPM2 is ADP-ribose (ADPR), a hydrolysis product of cADPR [60-63]. Indeed, cADPR also can activate the TRPM2 channel and the action of both molecules is synergistic, such that in the presence of low concentrations of $\mathrm{ADPR}$, the $\mathrm{EC}_{50}$ value of $\mathrm{cADPR}$ for activating the channel is greatly reduced $[57,58]$.

Studies in insulinoma cells and pancreatic islets show that the physiological consequence of the cADPR-dependent $\mathrm{Ca}^{2+}$ influx via TRPM2 is stimulation of insulin secretion $[56,64]$. Evidence also points to TRPM2 being a temperature sensor in the cells, whose activity is modulated by cADPR [56]. In neuronal cells, cADPR activates TRPM2 in a temperature dependent manner similar to that observed in the islet cells and is responsible for signaling oxytocin release $[65,66]$. In human bone marrow mesenchymal stem cells, modulation of TRPM2 by cADPR increases the frequency of $\mathrm{Ca}^{2+}$ oscillation, resulting in enhanced cell proliferation $[67,68]$.

\section{NAADP targets the two-pore channels in ly- sosomes}

That NAADP targets a novel $\mathrm{Ca}^{2+}$-release mechanism distinct from all known mechanisms was clear from the vary start. This is because the NAADP-mechanism is insensitive to all known inhibitors of the $\mathrm{IP}_{3^{-}}$, cADPR- and RyR-mechanisms $[3,11]$. The only way to block the mechanism is to self-desensitize it using high concentrations of NAADP $[69,70]$. That NAADP targets a specific and novel receptor was also clear, because any structural modifications on either the 2 '-phosphate, the N6-amino group, or the carboxyl group on the nicotinic acid moiety, render it inactive [71]. Even the $\mathrm{Ca}^{2+}$ stores it targets are separate from the ER. This was first shown by fractionation of the sea urchin egg homogenates. The NAADP-responsive organelles were found at the bottom of the Percoll density gradients, well separated from the cADPR-sensitive ER that were on the top of the gradient [72]. More convincingly, in situ stratification of the organelles in live sea urchin eggs using centrifugation combined with $\mathrm{Ca}^{2+}$-imaging, showed that the NAADP-sensitive stores were located at a pole of the stratified eggs that was 
separate and opposite to that of the cADPR- and $\mathrm{IP}_{3}$ - sensitive stores [73]. The distinctive organelles were subsequently identified as the reserve granules, a lysosome-related organelle in the eggs [74]. The finding was confirmed in mammalian cells as well $[31,75]$ (reviewed in [76]).

Searches were thus directed at ion channels localized in the lysosomes as possible candidate targets for NAADP. The two-pore channels (TPC 1-3) are members of a superfamily of voltage-gated ion channels and are localized in the lysosomes. In plant, TPC1 is found to mediate $\mathrm{Ca}^{2+}$ release from vacuoles [77]. Transfection of TPC into HEK293 cells resulted in its expression in the lysosomes. Specific NAADP binding to lysosomes increased and the cells became responsive to NAADP, indicating TPC is the target of NAADP [78]. A similar conclusion was reached by two other independent groups $[79,80]$.

Further support came from direct measurements of the NAADP-dependent currents through the TPC, using isolated lysosomes that were enlarged by vacuolin treatment and patched using a glass chip-based technique. The permeability of the TPC was found to be at least 1000-fold more selective for $\mathrm{Ca}^{2+}$ than for $\mathrm{K}^{+}$and was activatable by NAADP only when the intralysosomal $\mathrm{pH}$ was acidic [81]. The amino acid Glu643 in the putative pore region was identified as critical for the $\mathrm{Ca}^{2+}$ selectivity and its mutation to alanine reduced the permeability ratio of $\mathrm{Ca}^{2+}$ to $\mathrm{K}^{+}$by more than 120 times [81]. Similar results were obtained using immunopurified TPCs that were reconstituted into lipid bilayers. The single channel $\mathrm{Ca}^{2+}$ conductance of about $15 \mathrm{pS}$ was measured, which is 4 or 8 times less than that of the $\mathrm{IP}_{3}$-recpetor or RyR, respectively. The purified TPC also showed enriched specific binding to NAADP [82,83]. Collectively, these results leave little doubt that the TPCs are the endogenous targets of NAADP (reviewed in [84]).

\section{Enzymatic synthesis of cADPR by CD38}

As described above, it was the presence of the enzymatic activity in sea urchin egg homogenates converting NAD to cADPR that had led to its discovery (Figure 2). This enzymatic activity was not limited to sea urchin egg homogenates but was wide spread among mammalian tissue extracts as well [85]. The first purified enzyme that catalyzes the cyclization of NAD to cADPR was a soluble protein of $30 \mathrm{kD}$ from Aplysia [86,87]. The enzyme was previously thought to be a common NADase that hydrolyzes NAD to ADPR [86], as cADPR was a hitherto unknown molecule. The enzymatic product was eventually shown to be, in fact, cADPR and not ADPR. The Aplysia enzyme was thus named ADP-ribosyl cyclase (Cyclase) to distinguish it from common NADases [87]. A very convenient assay was later developed for measuring the cyclization of NAD by using nicotinamide guanine dinucleotide (NGD), an analog of
NAD, as substrate. The cADPR synthesizing enzymes, like the Cyclase, cyclize NGD to cyclic GDP-ribose, a fluorescent product, while conventional NADase hydrolyzes it to non-fluorescent GDP-ribose [88].

Based on the amino acid sequence of the Cyclase, CD38, an antigen expressed in lymphocytes, was found to be homologous [89]. CD38 was later shown to be able to, indeed, cyclize NAD to cADPR [90-93]. Unlike the Cyclase, CD38 catalyzes not only cADPR production but also the hydrolysis of cADPR to ADPR. In fact, when NAD is used as a substrate, the vast majority of the product is ADPR and not cADPR [90-93]. This again had raised confusion about whether CD38 was a Cyclase or a NADase. The issue was fortunately resolved by the newly available NGDassay $[88,94,95]$. The lack of a specific and sensitive assay for cADPR that had led to all the confusion has finally been overcome by the development of a fluorimetric assay for cADPR with nanomolar sensitivity and based on a coupled enzyme technique [96].

That CD38 is indeed responsible for synthesizing cADPR in tissues was shown by using CD38 knockout mice, whose endogenous cADPR in many tissues was greatly reduced [55]. The mice also manifest multiple defects relating to $\mathrm{Ca}^{2+}$ signaling, including that of insulin secretion [97], hormonal signaling in pancreatic acinar cells [98], migration of dendritic cell precursors [99], bone resorption [100], airway responsiveness [101], $\alpha$-adrenoceptor signaling in aorta [102], cardiac hypertrophy [103], susceptibility to bacterial infection [55], as well as social behavior in mice through modulation of oxytocin secretion [66]. In humans, the deletion of the CD38 gene may well be lethal since no CD38-negative individual has yet been identified in a large screen [104]. These results thus document the importance of the CD38/cADPR-pathway in regulating diverse physiological functions.

\section{Enzymatic synthesis of NAADP by CD38}

As described above, NAADP was discovered as a contaminant. That it is indeed naturally occurring was first shown in sea urchin sperm [105] and eggs [106], and later in cells from other species as well, including mammals [107]. That NAADP is derived from NADP, instead of NAD, and targets the lysosomal $\mathrm{Ca}^{2+}$-stores instead of the ER, would suggest that it should be synthesized by an enzyme different from CD38. Surprisingly, this is not the case. CD38, in fact, is multi-functional and can catalyze yet a base-exchange reaction, exchanging the nicotinamide group in NADP with nicotinic acid [108]. The product is NAADP. This reaction occurs only in acidic $\mathrm{pH}$, while the cyclization and hydrolysis of $\mathrm{NAD}(\mathrm{P})$ occur optimally at physiological $\mathrm{pH}$. This remarkable property of CD38 has now been elucidated by using X-ray crystallography, as will be described below.

That CD38 is responsible for the endogenous synthesis of NAADP was shown using knockout mice, whose hepatic 
stellate cells exhibited altered angiotensin-signaling that is attributable to their inability to elevate the cellular levels of NAADP in response to angiotensin [109]. Similar results were found in lymphokine-activated killer cells. Cells from the knockout mice no longer could elevate NAADP levels in response to IL8 [110]. Likewise, wild type pancreatic acinar cells responded to physiological concentrations of CCK with elevation of intracellular NAADP and $\mathrm{Ca}^{2+}$, but both were blocked in the acinar cells from the knockout mice [111].

\section{Structure and catalytic mechanism of CD38}

CD38 is thus a highly unusual enzyme that can use either NAD or NADP (with nicotinic acid) as substrates and convert it to cADPR or NAADP, respectively. How this can be accomplished by CD38 has now been elucidated to atomic resolution using X-ray crystallography and site-directed mutagenesis. Human CD38 is a membrane protein consisting of a short amino tail of 21 residues, a transmembrane segment of 23 hydrophobic residues and a large carboxyl domain (C-domain) of 256 residues [112]. There are also four glycosylation sites in the $\mathrm{C}$-domain. These features make CD38 a difficult candidate for crystallography.

The effort had thus directed first toward its homolog, the Aplysia Cyclase, which is a soluble protein of 258 residues and without glycosylation. The crystal structure shows that it is a bean-shaped molecule with a central cleft. The amino portion consists mainly of helices, while all the $\beta$-structures are in the carboxyl portion [113]. Confirming the crosslinking studies in solution [114], the Cyclase is also crystallized as a homo-dimer. The ten cysteines that are conserved with CD38 are all paired as disulfides. The active site was then identified by co-crystallization with nicotinamide [115], a co-substrate for the base-exchange reaction. Residues at the site were systematically mutated to identify the catalytic residue as Glu179.

The crystal structure of the C-domain of CD38 reveals a high degree of structural homology with the Aplysia Cyclase [116]. The removal of the amino tail and the transmembrane segment, together with the mutation of the glycosylation sites, makes the domain crystallizable and produce structures with resolution as high as $1.5 \AA[117,118]$. Glu226, which is equivalent to Glu179 in the Aplysia Cyclase, is identified as the catalytic residue as well [119]. Two other residues, Glu146 and Thr221, are shown to be the determinants that regulate the cyclization and hydrolysis reactions catalyzed by CD38. Thus, mutating Glu146 to alanine and Thr221 to phenylalanine converts CD38 to a Cyclase that produces mainly cADPR, instead of ADPR, from NAD. In fact, the catalytic properties of human CD38 and the Aplysia Cyclase can be inter-converted by mutating the equivalent residues respectively $[120,121]$.

Glu146 in CD38, together with Asp155, also controls the base-exchange reaction, particularly its acidic $\mathrm{pH}$ dependency described above [122]. The negative charges of these residues electrostatically repel the similarly charged nicotinic acid at physiological $\mathrm{pH}$ and prevent its entry into the active site. Mutating the residues to uncharged amino acids eliminated the acidic dependency of the base-exchange reaction [122]. All the equivalent residues in the Cyclase also function similarly, showing the high degree of structural and functional conservation between human CD38 and the Aplysia Cyclase, even though the two species had diverged for hundreds of millions of years.

The entry of the substrate into the active site of CD38, the formation of the enzyme intermediates and the substrate cyclization process have all been captured by crystallography. Mutating the catalytic residue inactivates CD38 and allows its substrate complexes to be visualized by crystallography $[117,123]$. NAD enters the active site pocket of CD38 with the nicotinamide end first. The catalytic Glu226 then forms hydrogen bonding with the hydroxyl groups of the terminal ribose, leading to the cleavage of the glycosidic bond and the release of the nicotinamide. An intermediate is formed. Both covalent [124] and non-covalent [123,124] intermediates of CD38 have been observed, depending on the substrate. With arabinosyl-2'-fluoro-deoxy-nicotinamide adenine dinucleotide (ara- ${ }^{\prime}$ F-NAD) as substrate, an analog of NAD, Glu226 forms a covalent linkage with the anomeric carbon (C1R) of the terminal ribose [125], as shown in Figures 3 and 4 . This anchors one end of the substrate to the active site and allows the folding of the adenine end during the cyclization to be observed.

Dynamic states of the cyclization of NAD have been captured in a single crystal of either CD38 or the Aplysia Cyclase [120,125]. CD38 generally crystallizes with two molecules in each asymmetric crystal unit. However, when the covalent intermediate is formed with ara-2'F-NAD, CD38 crystallizes in the orthorhombic form, in the P $2{ }_{1} 2_{1} 2_{1}$ space group, with six molecules in the crystal unit, as shown in Figure 3 [125]. Each molecule has a covalent intermediate at the active site and all of them have different conformations that can be grouped into two classes. The N1intermediates have the $\mathrm{N} 1$ of the adenine pointing toward $\mathrm{C} 1 \mathrm{R}$ of the terminal ribose, the cyclization site (left side in Figure 3), while the N7-intermediates have the N7 of the adenine pointing toward $\mathrm{C} 1 \mathrm{R}$ instead. The CD38 molecules in the crystal unit that have the N1-intermediates are all adjacent and are colored with different shades of blue in Figure 3, while those have the N7- intermediates are colored with shades of yellow. When the N1-molecules are aligned and all the N1-intermediates superimposed, it can be seen that their conformations represent states of folding of the adenine toward the site of cyclization (Figure 4A). In the closest approach, the distance between N1 and C1R is $3.2 \AA$, close enough for cyclization to occur. In the N7-conformation (Figure 4B), the distance becomes $9.6 \AA$ (Figure 3), too far for linkage and thus representing a nonproductive 


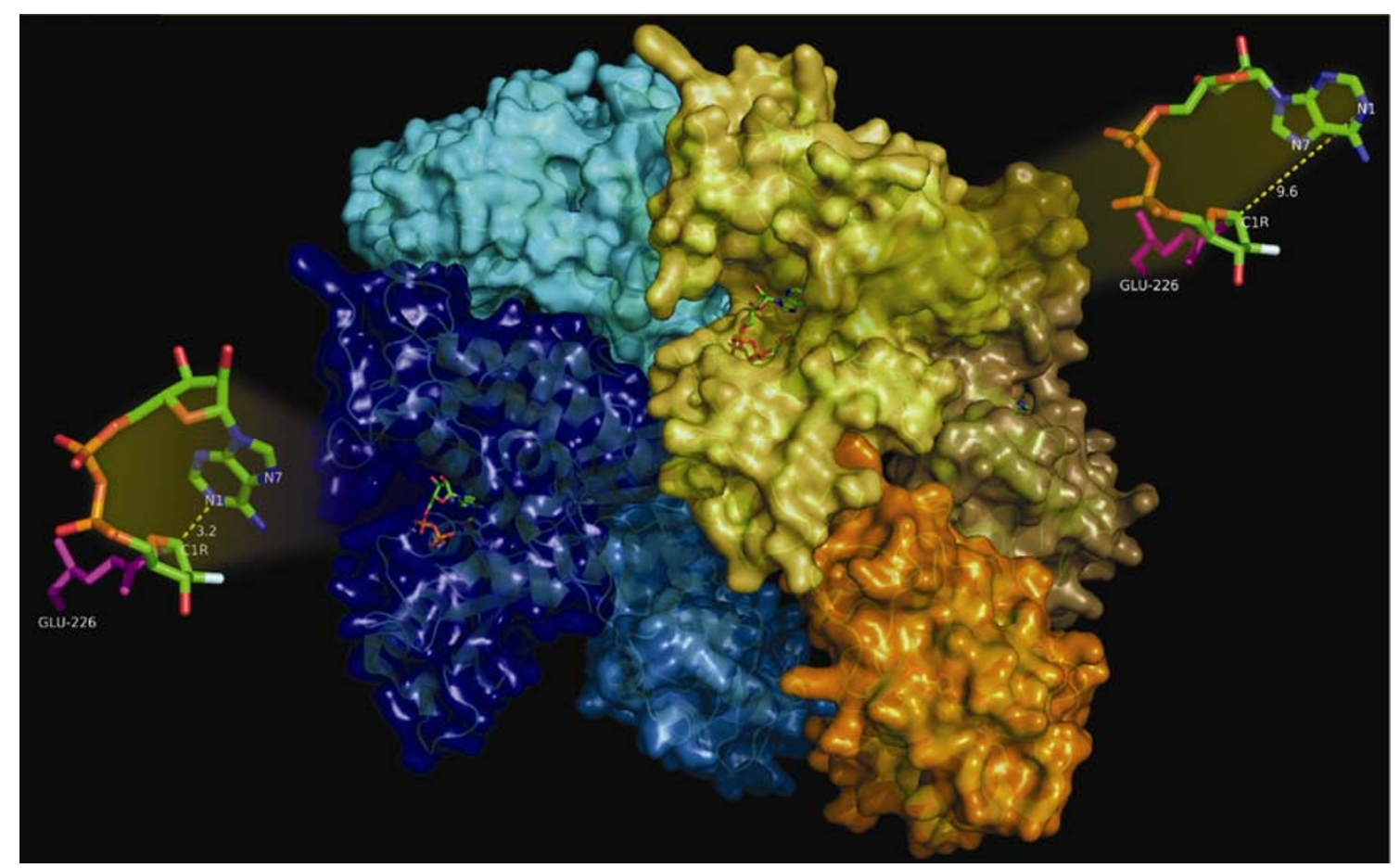

Figure 3 Conformers of CD38. Human CD38 can be crystallized with six molecules in a crystal asymmetric unit. The surface views of these molecules are shown. Three of them contain the covalent substrate intermediate that is in the N1-configuration as shown in the inset on the left. In this configuration, the $\mathrm{N} 1$ of adenine in the intermediate is anomeric carbon (C1R) of the ribose, the cyclization site. These conformers of CD38 are colored in different shades of blue. The other three conformers are colored in shades of yellow and contain the intermediates in the N7-configuration, as shown in the inset in the right. In this configuration the N7 of the adenine is pointing toward the C1R instead of the N1. All the intermediates form a covalent linkage with Glu226, which is shown as sticks and colored magenta. The color code for the intermediate is nitrogen: blue, carbon: green, oxygen: red, and fluorine: cyan.

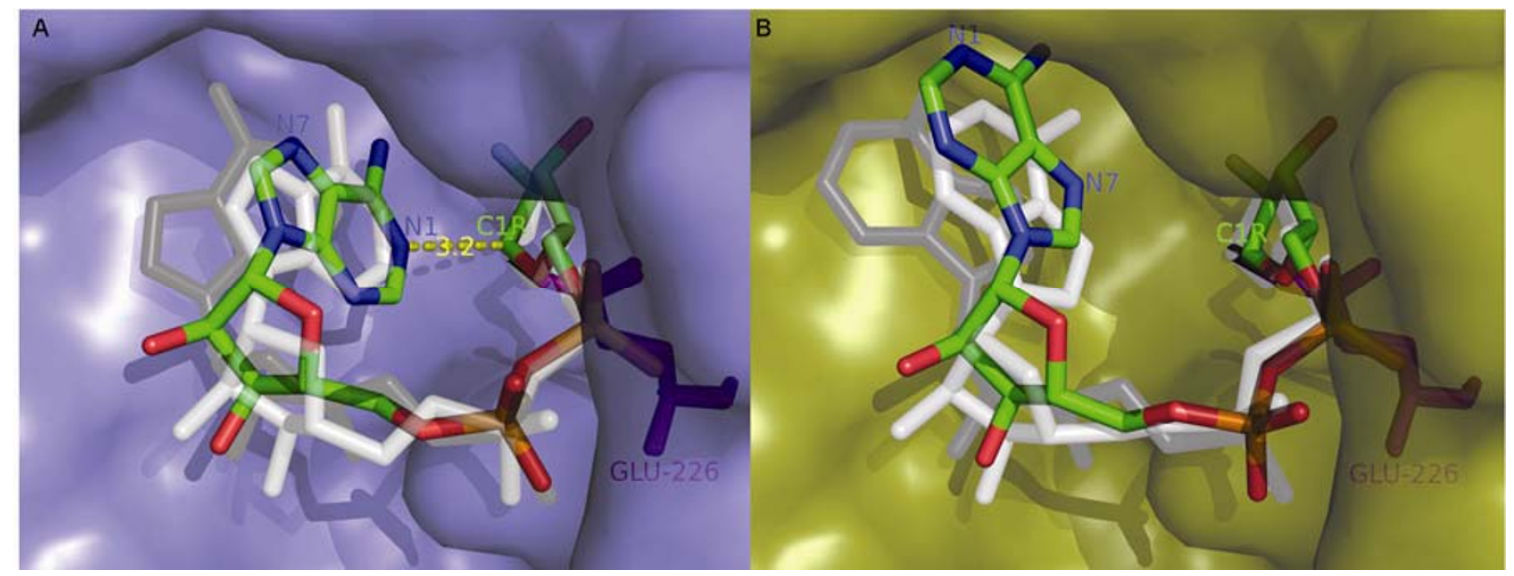

Figure 4 Dynamic states of the cyclization of the NAD analog captured in the conformers in a single crystal. The conformers of CD38 in the asymmetric crystal unit are aligned and superimposed. The three intermediates at the active site, which are in the N1-configuration, are superimposed and shown in A. The intermediate that has the $\mathrm{N} 1$ of the adenine closest $(3.2 \AA)$ to the cyclization site $(\mathrm{C} 1 \mathrm{R})$ is colored by its elements. The color coding is the same as in Figure 3. The other two are colored white and grey, respectively, and the N1 is farther away from the C1R, representing dynamic states of cyclization. The other three conformers that have the intermediates in the N7-configuration are shown superimposed and shown in B.

state.

Similar observation has previously been made in the Aplysia Cyclase [120]. The conformation of the covalent intermediate in each of the two molecules in the crystal unit corresponds, respectively, to the N1- and N7- conformation, seen in CD38. The two conformations are actually equivalent because they can be mapped to each other by sin- gle-bond rotations [120]. Using NMR, it has been shown that the conformational features of the multiple molecules or 'conformers' in the crystal asymmetric unit correspond to those observed in solution for the ensemble of NMR conformers [126]. They are thus not artifactual, due to crystal packing, but may actually represent the true dynamic states of the cyclization of NAD by CD38 and the Cyclase. 


\section{Membrane topology and regulation of CD38}

Elucidation of how the endogenous synthesis of cADPR and NAADP is regulated represents the next frontier of the field. The first indication obtained in sea urchin eggs is that the cADPR-production is stimulated by a cGMP-dependent process, most likely through phosphorylation of the enzyme $[127,128]$. It has been proposed that cADPR and NAADP production may be differentially regulated by receptor-coupled second messengers, cGMP and cAMP, respectively [129]. However, cGMP-independent cADPR synthesis had also been found in the eggs [130]. In mammalian cells, both cGMP- [110,131-133] and cAMP-dependent [134-137] cADPR-synthesis have been reported. Likewise, in lymphokine-activated killer cells, NAADP synthesis is stimulated by both cAMP and cGMP [110].

In granulocytes, treatments with 8Br-cAMP, a cellpermeant analog of cAMP, can increase serine phosphorylation of CD38 [135]. What is not known is which part of CD38 is phosphorylated, whether it is the catalytic $\mathrm{C}$-domain or the amino tail. Intuitively, one would expect the phosphorylation site should be in the catalytic domain and may even be close to the active site, such that the enzymatic activity can be effectively modulated. This would necessitate the catalytic domain of CD38 to be facing the cytosol, in other words, a type-III membrane protein. This is, however, contrary to the general belief that CD38 is a type-II membrane protein, at least in the lymphocytes, with its C-domain on the outside [112].

The type-II membrane topology also raises other problems of functionality, namely, substrate access and product targeting. Both NAD and the $\mathrm{Ca}^{2+}$ stores that the products, cADPR and NAADP, target are located in the cytosol. This "topological paradox" has been addressed [138,139]. It is shown that NAD can leak out of the cell via connexin hemi-channels $[140,141]$ and made available to the type-II CD38, while the product, cADPR, produced is transported back into the cell by nucleoside transporters present in the plasma membrane [142,143]. This pathway is depicted in Figure 5. Both connexin and nucleoside transporters are also present in the organellar membranes and can perform similar functions for the type-II CD38 that is intracellular (reviewed in $[138,139]$ ). Indeed, it is well documented that CD38 is, by no means, a purely surface protein, but is expressed also in organelles [144-146], including the nucleus [147-149].

Another alternative solution to this topological conundrum is the possible co-existence of two forms of CD38, type-II and III in cells, as depicted in Figure 5. This possibility is novel but may offer a more straightforward resolution to the conundrum. It is generally believed that the polarity of membrane proteins is determined predominantly by

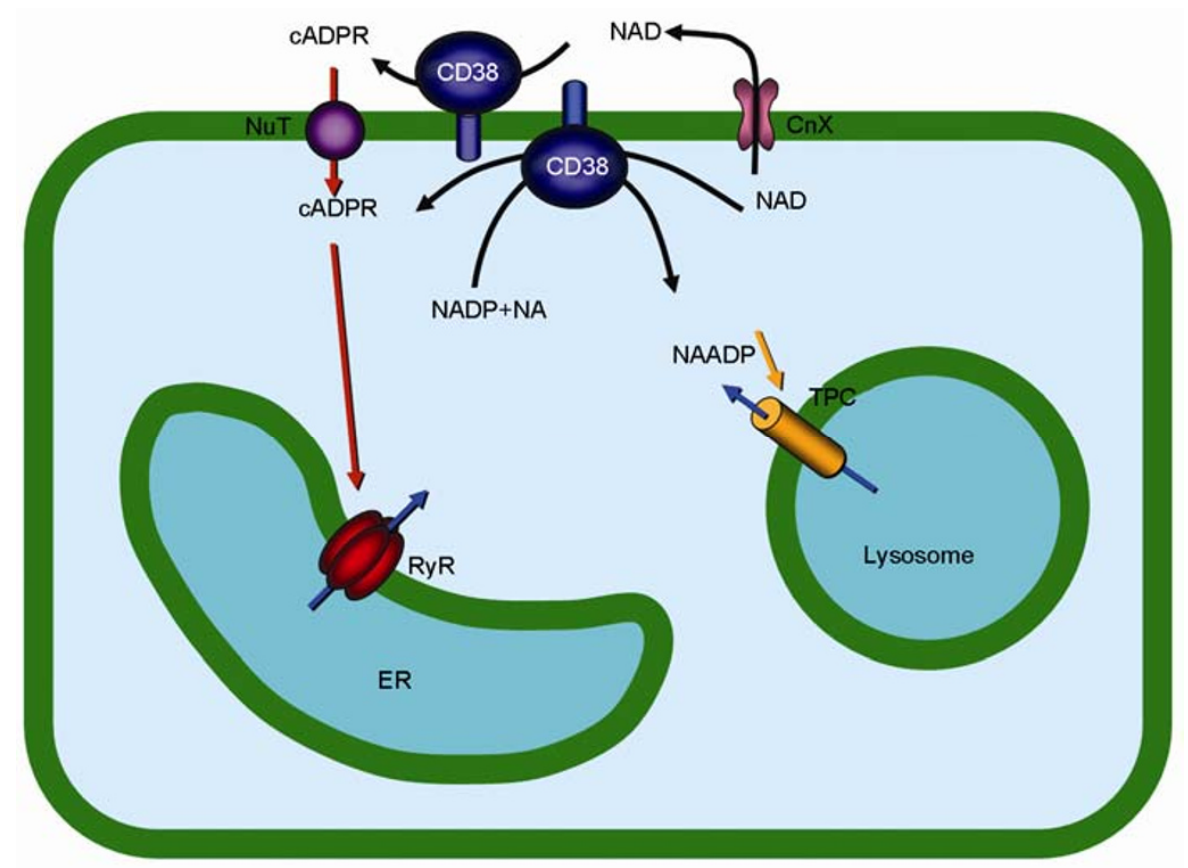

Figure 5 Schematic of the cADPR/NAADP/CD38-signaling pathway. The target of cADPR is the ryanodine receptor (RyR), a Ca ${ }^{2+}$ release channel in the sarco/endoplasmic reticulum (ER), while that of NAADP is the two-pore channel (TPC) in the endolysosomes. Both cADPR and NAADP are synthesized by the membrane enzyme, CD38, which cyclizes NAD in a head-to-tail fashion to produce cADPR and can also catalyze a base-exchange reaction, exchanging the nicotinamide group in NADP with nicotinic acid (NA) to produce NAADP. In some cells, particularly lymphocytes, CD38 is expressed as a type-II membrane protein with the catalytic domain facing outside. The substrate NAD needs to exit the cell via connexin hemi-channels (CNX) to access CD38 and the product, cADPR, is transported back into the cell via nucleoside transporters (NuT) in the plasma membrane to exercise its Ca ${ }^{2+}$ signaling function. An alternative scheme also depicted is the existence of the putative type III-CD38 with its catalytic domain facing the cytosol. In this scheme, the substrates in the cytosol have direct access to CD38 and the catalytic domain is also amenable to regulation from the cytosol, such as by protein phosphorylation. 
charged residues flanking the hydrophobic core of the trans-membrane segment (reviewed in [150]). The side with the most net positive charge is generally cytosolic, the "positive inside rule". For CD38, there are four positive charges on each side of the trans-membrane segment, suggesting the possibility that both polarities can be expressed. Indeed, studies using a protease digestion technique [147] and immuno-gold electron-microscopy [148], have provided evidence that the nuclear CD38 may, in fact, be expressed as a type-III membrane protein.

That a membrane protein can adopt two opposite orientations has precedence. The bacterial multidrug transporter, EmrR, is a protein with four transmembrane helixes. As a functional transporter, it is a homo-dimer. The two identical monomers, however, are in opposite orientation, with the $\mathrm{N}$-terminus of one monomer faces the cytoplasm, while the other faces outside [151]. Another example is the prion protein, a type-II protein similar to CD38, which not only can be synthesized in two opposite trans-membrane orientations, but also in a glycosyl-phosphatidylinositol-linked form. Trans-acting protein factors have been described that can direct prion proteins toward different topologic fates [152-155].

One other important consideration for the putative type-III CD38 is the disulfides. CD38 has twelve cysteines in the catalytic domain that are all paired as disulfides [116]. It is a common belief that disulfides are formed only inside the ER, and not in the reductive environment of the cytosol. It is unclear that the type-III CD38, with its catalytic domain facing the cytosol, can form the disulfides. It should be noted that, although rare, a wide range of cytosolic proteins, including those involved in chaperone function, signal transduction, cell growth, etc., have been found to contain inter- as well as intra-molecular disulfide bonds in both mammalian cells and bacteria [156-158].

The critical question of disulfide in CD38 has recently been directly addressed. A novel form of CD38 was engineered that expressed efficiently in the cytosol [159]. It was shown that it not only forms intact disulfides but is also fully active in elevating the cytosolic cADPR levels. This engineered cytosolic form of CD38 is thus a novel example challenging the general belief that cytosolic proteins do not possess disulfides and suggests that the information for disulfide formation may be encoded in the primary sequence of CD38. CD38 thus appears to be a novel membrane protein specifically designed to function in both the reductive cytosol as well as the oxidative external environment.

\section{Conclusion}

NAD(P) was discovered in 1906 [160] and subsequent work by Warburg and others in the 1930s, established that its primary function is serving as co-enzyme(s) for the redox reactions in cells [161]. Half a century had since passed before the emergence of evidence indicating that NAD(P) also has important $\mathrm{Ca}^{2+}$ signaling functions, through serving as substrates for cADPR and NAADP. This unexpected discovery had been greeted with healthy doses of skepticism and trivialization. The field has, however, persevered and advanced. Thousands of articles on the subject have been published and the topics of cyclic ADP-ribose or NAADP, have received progressive increase in citation from 1989 to 2010, totaling over 76000 times. In the past two decades, we have seen the identification of the targets of CADPR and NAADP, the elucidation of the enzymatic mechanism of their synthesis to atomic resolution, the documentation of the physiological importance of the signaling pathway through CD38 gene ablation, and the emerging of lysosome-related acidic organelles as fully functional, regulated and relevant, $\mathrm{Ca}^{2+}$ stores. The progress of the field has brought forth many unanticipated findings and, in some cases, they often challenge the conventional wisdom and dogma. In the immediate future, the regulation of CD38 and the ADP-ribosyl Cyclase represents a new frontier that is likely to usher in new results in membrane protein topology and its relationship with signaling function.

I thank Rich Graeff for editing the manuscript. This work was supported by the Research Grants Council of Hong Kong (Grant Nos. 769107, 768408, 769309 and 770610) and the National Natural Science Foundation of China/the Research Grants Council of Hong Kong (Grant No. N_HKU 722/08).

1 Streb H, Irvine R F, Berridge M J, et al. Release of $\mathrm{Ca}^{2+}$ from a nonmitochondrial intracellular store in pancreatic acinar cells by inositol-1,4,5-trisphosphate. Nature, 1983, 306: 67-69

2 Bosanac I, Alattia J R, Mal T K, et al. Structure of the inositol 1,4,5-trisphosphate receptor binding core in complex with its ligand. Nature, 2002, 420: 696-700

3 Clapper D L, Walseth T F, Dargie P J, et al. Pyridine nucleotide metabolites stimulate calcium release from sea urchin egg microsomes desensitized to inositol trisphosphate. J Biol Chem, 1987, 262: 9561-9568

4 Lee H C, Walseth T F, Bratt G T, et al. Structural determination of a cyclic metabolite of $\mathrm{NAD}^{+}$with intracellular $\mathrm{Ca}^{2+}$-mobilizing activity. J Biol Chem, 1989, 264: 1608-1615

5 Clapper D L, Lee H C. Inositol trisphosphate induces $\mathrm{Ca}^{+2}$ - release from non-mitochondrial stores in sea urchin egg homogenates. J Biol Chem, 1985, 260: 13947-3954

6 Mazia D. The release of calcium in Arbacia eggs on fertilization. J Cell Comp, 1937, Physiol, 10: 291-304

7 Lee H C, Aarhus R, Levitt D. The crystal structure of cyclic ADP-ribose. Nature Struct Biol, 1994, 1: 143-144

8 Shuto S, Fukuoka M, Manikowsky A, et al. Total synthesis of cyclic ADP-carbocyclic-ribose, a stable mimic of $\mathrm{Ca}^{2+}$-mobilizing second messenger cyclic ADP-Ribose. J Am Chem Soc, 2001, 123: 8750-8759

9 Potter B V L, Walseth T F. Medicinal chemistry and pharmacology of cyclic ADP-ribose. Curr Mol Med, 2004, 4: 303-312

10 Walseth T F, Aarhus R, Zeleznikar R J Jr., et al. Determination of endogenous levels of cyclic ADP-ribose in rat tissues. Biochim Biophys Acta, 1991, 1094: 113-120

11 Lee H C, Aarhus R. A derivative of NADP mobilizes calcium stores insensitive to inositol trisphosphate and cyclic ADP-ribose. J Biol Chem, 1995, 270: 2152-2157 
12 Lam C M, Yeung P K, Lee H C, et al. Cyclic ADP-ribose links metabolism to multiple fission in the dinoflagellate Crypthecodinium cohnii. Cell Cal, 2009, 45: 346-357

13 Navazio L, Bewell M A, Siddiqua A, et al. Calcium release from the endoplasmic reticulum of higher plants elicited by the NADP metabolite nicotinic acid adenine dinucleotide phosphate. Proc Natl Acad Sci USA, 2000, 97: 8693-8698

$14 \mathrm{Wu}$ Y, Kuzma J, Marechal E, et al. Abscisic acid signaling through cyclic ADP-ribose in plants. Science, 1997, 278: 2126-2130

15 Johnson J D, Misler S. Nicotinic acid-adenine dinucleotide phosphate-sensitive calcium stores initiate insulin signaling in human beta cells. Proc Natl Acad Sci USA, 2002, 99: 14566-14571

16 Podesta M, Zocchi E, Pitto A, et al. Extracellular cyclic ADP-ribose increases intracellular free calcium concentration and stimulates proliferation of human hemopoietic progenitors. FASEB J, 2000, 14: 680-690

17 Lee H C. Cyclic ADP-ribose and NAADP. Structures, Metabolism and Functions. Dordrecht: Kluwer Academic Publishers, 2002

18 Kuroda $\mathrm{R}$, Kontani $\mathrm{K}$, Kanda $\mathrm{Y}$, et al. Increase of cGMP, cADP-ribose and inositol 1,4,5-trisphosphate preceding $\mathrm{Ca}^{2+}$ transients in fertilization of sea urchin eggs. Dev, 2001, 128: 4405-4414

19 Leckie C, Empson R, Becchetti A, et al. The NO pathway acts late during the fertilization response in sea urchin eggs. J Biol Chem, 2003, 278: 12247-12254

20 Dargie P J, Agre M C, Lee H C. Comparison of $\mathrm{Ca}^{2+}$ mobilizing activities of cyclic ADP-ribose and inositol trisphosphate. Cell Regul, 1990, 1: 279-290

21 Galione A, McDougall A, Busa W B, et al. Redundant mechanisms of calcium-induced calcium release underlying calcium waves during fertilization of sea urchin eggs. Science, 1993, 261: 348-352

22 Lee H C, Aarhus R, Walseth T F. Calcium mobilization by dual receptors during fertilization of sea urchin eggs. Science, 1993, 261: 352-355

23 Lee H C. Calcium signaling: NAADP ascends as a new messenger. Curr Biol, 2003, 13: R186-R188

24 Lee $\mathrm{H}$ C. Nicotinic acid adenine dinucleotide phosphate (NAADP)-mediated calcium signaling. J Biol Chem, 2005, 280: 33693-33696

25 Cancela J M. Specific $\mathrm{Ca}^{2+}$ signaling evoked by cholecystokinin and acetylcholine: The roles of NAADP, cADPR, and IP3. Annu Rev Physiol, 2001, 63: 99-117

26 Cancela J M, Churchill G C, Galione A. Coordination of agonist-induced $\mathrm{Ca}^{2+}$-signalling patterns by NAADP in pancreatic acinar cells. Nature, 1999, 398: 74-76

27 Yamasaki M, Thomas J M, Churchill G C, et al. Role of NAADP and cADPR in the induction and maintenance of agonist-evoked $\mathrm{Ca}^{2+}$ spiking in mouse pancreatic acinar cells. Curr Biol, 2005, 15: 874-878

28 Guse A H, Lee H C. NAADP: A universal $\mathrm{Ca}^{2+}$ trigger. Sci Signal, 2008, 1: re10

29 Arredouani A, Evans A M, Ma J, et al. An emerging role for NAADP-mediated $\mathrm{Ca}^{2+}$ signaling in the pancreatic beta-cell. Islets, 2010, 2: 323-330

30 Masgrau R, Churchill G C, Morgan A J, et al. NAADP: A new second messenger for glucose-induced $\mathrm{Ca}^{2+}$ responses in clonal pancreatic b-cells. Curr Biol, 2003, 13: 247-251

31 Yamasaki M, Masgrau R, Morgan A J, et al. Organelle selection determines agonist-specific $\mathrm{Ca}^{2+}$ signals in pancreatic acinar and beta cells. J Biol Chem, 2004, 279: 7234-7240

32 Galione A, Lee H C, Busa W B. $\mathrm{Ca}^{2+}$-induced $\mathrm{Ca}^{2+}$ release in sea urchin egg homogenates: modulation by cyclic ADP-ribose. Science, 1991, 253: 1143-1146

33 Lee H C. Potentiation of calcium- and caffeine-induced calcium release by cyclic ADP-ribose. J Biol Chem, 1993, 268: 293-299

34 Meszaros L G, Bak J, Chu A. Cyclic ADP-ribose as an endogenous regulator of the non-skeletal type ryanodine receptor $\mathrm{Ca}^{2+}$ channel. Nature, 1993, 364: 76-79

35 Chen S R W, Li X L, Ebisawa K, et al. Functional characterization of the recombinant type $3 \mathrm{Ca}^{2+}$ release channel (ryanodine receptor) expressed in HEK293 cells. J Biol Chem, 1997, 272: 24234-24246

36 Copello J A, Qi Y, Jeyakumar L H, et al. Lack of effect of cADP-ribose and NAADP on the activity of skeletal muscle and heart ryanodine receptors. Cell Cal, 2001, 30: 269-284

37 Fruen B R, Mickelson J R, Shomer N H, et al. Cyclic ADP-ribose does not affect cardiac or skeletal muscle ryanodine receptors. FEBS Lett, 1994, 352: 123-126

38 Tian C, Shao C H, Moore C J, et al. Gain of Function of cardiac ryanodine receptor in a rat model of type 1 diabetes. Cardiovasc Res, 2011, doi: 10.1093/cvr/cvr076

39 Lokuta A J, Darszon A, Beltran C, et al. Detection and functional characterization of ryanodine receptors from sea urchin eggs. J Physiol, 1998, 510, 1: 155-164

40 Tang W X, Chen Y F, Zou A P, et al. Role of FKBP12.6 in cADPR-induced activation of reconstituted ryanodine receptors from arterial smooth muscle. Am J Physiol Heart Circ Physiol, 2002, 282: H1304-1310

41 Cui Y, Galione A, Terrar D A. Effects of photoreleased cADP-ribose on calcium transients and calcium sparks in myocytes isolated from guinea-pig and rat ventricle. Biochem J, 1999, 342: 269-273

42 Macgregor A T, Rakovic S, Galione A, et al. Dual effects of cyclic ADP-ribose on sarcoplasmic reticulum $\mathrm{Ca}^{2+}$ release and storage in cardiac myocytes isolated from guinea-pig and rat ventricle. Cell Cal, 2007, 41: 537-546

43 Zhang X, Tallini Y N, Chen Z, et al. Dissociation of FKBP 12.6 from ryanodine receptor type 2 is regulated by cyclic ADP-ribose but not \{beta\}-adrenergic stimulation in mouse cardiomyocytes. Cardiovasc Res, 2009, 84: 253-262

44 Zheng J, Wenzhi $\mathrm{B}$, Miao $\mathrm{L}$, et al. $\mathrm{Ca}(2+)$ release induced by cADP-ribose is mediated by FKBP12.6 proteins in mouse bladder smooth muscle. Cell Cal, 2010, 47: 449-457

45 Ogunbayo O A, Zhu Y, Rossi D, et al. cADPR activates ryanodine receptors while NAADP activates two pore domain channels. J Biol Chem, 2011, 286: 9136-9140

46 Lee H C, Aarhus R, Graeff R, et al. Cyclic ADP ribose activation of the ryanodine receptor is mediated by calmodulin. Nature, 1994, 370: 307-309

47 Lee H C, Aarhus R, Graeff R M. Sensitization of calcium-induced calcium release by cyclic ADP-ribose and calmodulin. J Biol Chem, 1995, 270: 9060-9066

48 Tanaka Y, Tashjian A H Jr. Calmodulin is a selective mediator of $\mathrm{Ca}^{2+}$-induced $\mathrm{Ca}^{2+}$ release via the ryanodine receptor-like $\mathrm{Ca}^{2+}$ channel triggered by cyclic ADP-ribose. Proc Natl Acad Sci USA, 1995, 92: 3244-3248

49 Okabe E, Tsujimoto Y, Kobayashi Y. Calmodulin and cyclic ADP-ribose interaction in $\mathrm{Ca}^{2+}$ signaling related to cardiac sarcoplasmic reticulum: superoxide anion radical-triggered $\mathrm{Ca}^{2+}$ release. Antioxid Redox Signal, 2000, 2: 47-54

50 Thomas J M, Summerhill R J, Fruen B R, et al. Calmodulin dissociation mediates desensitization of the cADPR-Induced $\mathrm{Ca}^{2+}$ release mechanism. Curr Biol, 2002, 12: 2018-2002

51 Wang Y X, Zheng Y M, Mei Q B, et al. FKBP12.6 and cADPR regulation of $\mathrm{Ca}^{2+}$ release in smooth muscle cells. Am J Physiol, 2003 , 286: C538-C546

52 Noguchi N, Takasawa S, Nata K, et al. Cyclic ADP-ribose binds to FK506-binding protein 12.6 to release $\mathrm{Ca}^{2+}$ from islet microsomes. $\mathrm{J}$ Biol Chem, 1997, 272: 3133-3136.

53 Morita K, Kitayama T, Kitayama S, et al. Cyclic ADP-ribose requires FK506-binding protein to regulate intracellular $\mathrm{Ca}^{2+}$ dynamics and catecholamine release in acetylcholine-stimulated bovine adrenal chromaffin cells. J Pharmacol Sci, 2006, 101: 40-51

54 Guse A H, Berg I, Dasilva C P, et al. $\mathrm{Ca}^{2+}$ entry induced by cyclic ADP-ribose in intact T-lymphocytes. J Biol Chem, 1997, 272: 8546-8550

55 Partida-Sanchez S, Cockayne D, Monard S, et al. Cyclic ADP-ribose production by $\mathrm{CD} 38$ regulates intracellular calcium release, extracellular calcium influx and chemotaxis in neutrophils and is required for bacterial clearance in vivo. Nature Med, 2001, 7: 
1209-1216

56 Togashi K, Hara Y, Tominaga T, et al. TRPM2 activation by cyclic ADP-ribose at body temperature is involved in insulin secretion. EMBO J, 2006, 25: 1804-1815

57 Kolisek M, Beck A, Fleig A, et al. Cyclic ADP-ribose and hydrogen peroxide synergize with ADP-ribose in the activation of TRPM2 channels. Mol Cell, 2005, 18: 61-69

58 Lange I, Penner R, Fleig A, et al. Synergistic regulation of endogenous TRPM2 channels by adenine dinucleotides in primary human neutrophils. Cell Cal, 2008, 44: 604-615

59 Eisfeld J, Luckhoff A. TRPM2. Handb Exp Pharmacol. 2007, 179: $237-252$

60 Gasser A, Glassmeier G, Fliegert R, et al. Activation of $\mathrm{T}$ cell calcium influx by the second messenger ADP-ribose. J Biol Chem, 2005, 281: 2489-2496

61 Heiner I, Eisfeld J, Warnstedt M, et al. Endogenous ADP-ribose enables calcium-regulated cation currents through TRPM2 channels in neutrophil granulocytes. Biochem J, 2006, 9: 9

62 Starkus J, Beck A, Fleig A, et al. Regulation of TRPM2 by extra- and intracellular calcium. J Gen Physiol, 2007, 4: 427-440

63 Perraud A L, Fleig A, Dunn C A, et al. ADP-ribose gating of the calcium-permeable LTRPC2 channel revealed by Nudix motif homology. Nature, 2001, 411: 595-599

64 Togashi $\mathrm{K}$, Inada $\mathrm{H}$, Tominaga $\mathrm{M}$. Inhibition of the transient receptor potential cation channel TRPM2 by 2-aminoethoxydiphenyl borate (2-APB). Br J Pharmacol, 2008, 153: 1324-1330

65 Amina S, Hashii M, Ma W J, et al. Intracellular calcium elevation induced by extracellular application of cyclic-ADP-ribose or oxytocin is temperature-sensitive in rodent NG108-15 neuronal cells with or without exogenous expression of human oxytocin receptors. J Neuroendocrinol, 2010, 5: 460-466

66 Jin D, Liu H X, Hirai H, et al. CD38 is critical for social behaviour by regulating oxytocin secretion. Nature, 2007, 446: 41-45

67 Scarfi S, Ferraris C, Fruscione F, et al. Cyclic ADP-ribose-mediated expansion and stimulation of human mesenchymal stem cells by the plant hormone abscisic acid. Stem Cells, 2008, 11: 2855-2864

68 Tao R, Sun H Y, Lau C P, et al. Cyclic ADP ribose is a novel regulator of intracellular $\mathrm{Ca}(2+)$ oscillations in human bone marrow mesenchymal stem cells. J Cell Mol Med, 2011, doi: 10.1111/j.1582-4934.2011.01263.x.

69 Aarhus R, Dickey D M, Graeff R M, et al. Activation and inactivation of $\mathrm{Ca}^{2+}$ release by $\mathrm{NAADP}^{+}$. J Biol Chem, 1996, 271: 8513-8516

70 Genazzani A A, Empson R M, Galione A. Unique inactivation properties of NAADP-sensitive $\mathrm{Ca}^{2+}$ release. J Biol Chem, 1996, 271: 11599-11602

71 Lee H C, Aarhus R. Structural determinants of nicotinic acid adenine dinucleotide phosphate important for its calcium-mobilizing activity. J Biol Chem, 1997, 272: 20378-20383

72 Lee H C. Modulator and messenger functions of cyclic ADP-ribose in calcium signaling. Re Prog Horm Res, 1996, 51: 355-88

73 Lee H C, Aarhus R. Functional visualization of the separate but interacting calcium stores sensitive to NAADP and cyclic ADP-ribose. J Cell Sci, 2000, 113: 4413-4420

74 Churchill G C, Okada Y, Thomas J M, et al. NAADP mobilizes $\mathrm{Ca}^{2+}$ from reserve granules, lysosome-related organelles, in sea urchin eggs. Cell, 2002, 111: 703-708

75 Kinnear N P, Boittin F X, Thomas J M, et al. LysosomeSarcoplasmic reticulum junctions: A trigger zone for calcium signalling by NAADP and endothelin-1. J Biol Chem, 2004, 279: 54319-54326

76 Galione A, Petersen O H. The NAADP Receptor: New receptors or new regulation? Mol Interv, 2005, 5: 73-79

77 Peiter E, Maathuis F J, Mills L N, et al. The vacuolar $\mathrm{Ca}^{2+}$-activated channel TPC1 regulates germination and stomatal movement. Nature, 2005, 434: 404-408

78 Calcraft P J, Ruas M, Pan Z, et al. NAADP mobilizes calcium from acidic organelles through two-pore channels. Nature, 2009, 459: $596-601$
79 Brailoiu E, Churamani D, Cai X, et al. Essential requirement for two-pore channel 1 in NAADP-mediated calcium signaling. J Cell Biol, 2009, 186: 201-209

80 Zong X, Schieder M, Cuny H, et al. The two-pore channel TPCN2 mediates NAADP-dependent $\mathrm{Ca}^{2+}$-release from lysosomal stores. Pflugers Arch, 2009, 458: 891-899

81 Schieder M, Roetzer K, Brueggemann A, et al. Characterization of two pore channel 2 (TPCN2) -mediated $\mathrm{Ca}^{2+}$ currents in isolated lysosomes. J Biol Chem, 2010, 285: 21219-21222

82 Ruas M, Rietdorf K, Arredouani A, et al. Purified TPC isoforms form NAADP receptors with distinct roles for $\mathrm{Ca}^{2+}$ signaling and endolysosomal trafficking. Curr Biol, 2010, Mar 24. [Epub ahead of print]

83 Pitt S J, Funnell T, Sitsapesan M, et al. TPC2 is a novel NAADP-sensitive $\mathrm{ca}^{2+}$-release channel, operating as a dual sensor of luminal $\mathrm{pH}$ and $\mathrm{Ca}^{2+}$. J Biol Chem, 2010, 285: 35039-35046

84 Galione A, Evans A M, Ma J, et al. The acid test: the discovery of two-pore channels (TPCs) as NAADP-gated endolysosomal $\mathrm{Ca}^{2+}$ release channels. Pflugers Arch, 2009, 458: 869-876

85 Rusinko N, Lee H C. Widespread occurrence in animal tissues of an enzyme catalyzing the conversion of $\mathrm{NAD}^{+}$into a cyclic metabolite with intracellular $\mathrm{Ca}^{2+}$-mobilizing activity. J Biol Chem, 1989, 264 : 11725-11731

86 Hellmich M R, Strumwasser F. Purification and characterization of a molluscan egg-specific NADase, a second-messenger enzyme. Cell Regul, 1991, 2: 193-202

87 Lee H C, Aarhus R. ADP-ribosyl cyclase: an enzyme that cyclizes $\mathrm{NAD}^{+}$into a calcium-mobilizing metabolite. Cell Regul, 1991, 2: 203-209

88 Graeff R M, Walseth T F, Fryxell K, et al. Enzymatic synthesis and characterizations of cyclic GDP-ribose. A procedure for distinguishing enzymes with ADP-ribosyl cyclase activity. J Biol Chem, 1994, 269: 30260-30267

89 States D J, Walseth T F, Lee H C. Similarities in amino acid sequences of Aplysia ADP-ribosyl cyclase and human lymphocyte antigen CD38. Trends Biochem Sci, 1992, 17: 495

90 Howard M, Grimaldi J C, Bazan J F, et al. Formation and hydrolysis of cyclic ADP-ribose catalyzed by lymphocyte antigen CD38. Science, 1993, 262: 1056-1059

91 Lee H C, Zocchi E, Guida L, et al. Production and hydrolysis of cyclic ADP-ribose at the outer surface of human erythrocytes. Biochem Biophys Res Commun, 1993, 191: 639-645

92 Takasawa S, Tohgo A, Noguchi N, et al. Synthesis and hydrolysis of cyclic ADP-ribose by human leukocyte antigen CD38 and inhibition of the hydrolysis by ATP. J Biol Chem, 1993, 268: 26052-26054

93 Kim H, Jacobson E L, Jacobson M K. Synthesis and degradation of cyclic ADP-ribose by NAD glycohydrolases. Science, 1993, 261: 1330-1333

94 Graeff R M, Mehta K, Lee H C. GDP-ribosyl cyclase activity as a measure of CD38 induction by retinoic acid in HL-60 cells. Biochem. Biophys Res Commun, 1994, 205: 722-727

95 Graeff R M, Walseth T F, Hill H K, et al. Fluorescent analogs of cyclic ADP-ribose: synthesis, spectral characterization, and use. Biochemistry, 1996, 35: 379-386

96 Graeff R, Lee H C. A novel cycling assay for cellular cyclic ADP-ribose with nanomolar sensitivity. Biochem J, 2002, 361: 379-384

97 Kato I, Yamamoto Y, Fujimura M, et al. CD38 disruption impairs glucose-induced increases in cyclic ADP-ribose, $\left[\mathrm{Ca}^{2+}\right]_{i}$ and insulin secretion. J Biol Chem, 1999, 274: 1869-1872

98 Fukushi Y, Kato I, Takasawa S, et al. Identification of cyclic ADP-ribose-dependent mechanisms in pancreatic muscarinic $\mathrm{Ca}^{2+}$ signaling using CD38 knockout mice. J Biol Chem, 2001, 276: 649-655

99 Partida-Sanchez S, Goodrich S, Kusser K, et al. Regulation of dendritic cell trafficking by the ADP-ribosyl cyclase CD38; Impact on the development of humoral immunity. Immunity, 2004, 20: 279-291

100 Sun L, Iqbal J, Dolgilevich S, et al. Disordered osteoclast formation 
and function in a CD38 (ADP-ribosyl cyclase)-deficient mouse establishes an essential role for CD38 in bone resorption. FASEB J, 2003, 17: 369-375

101 Deshpande D A, White T A, Guedes A G P, et al. Altered airway responsiveness in CD38 deficient mice. Am J Respir Cell Mol Biol, 2005, 32: 149-156

102 Mitsui-Saito M, Kato I, Takasawa S, et al. CD38 gene disruption inhibits the contraction induced by alpha-adrenoceptor stimulation in mouse aorta. J Vet Med Sci, 2003, 65: 1325-1330

103 Takahashi J, Kagaya Y, Kato I, et al. Deficit of CD38/cyclic ADP-ribose is differentially compensated in hearts by gender. Biochem Biophys Res Commun, 2003, 312: 434-440

104 Malavasi F, Deaglio S, Funaro A, et al. Evolution and function of the ADP ribosyl cyclase/CD38 gene family in physiology and pathology. Physiol Rev, 2008, 88: 841-886

105 Billington R A, Ho A, Genazzani A A. Nicotinic acid adenine dinucleotide phosphate (NAADP) is present at micromolar concentrations in sea urchin spermatozoa. J Physiol, 2002, 544.1: 107-112

106 Churchill G C, O’Neill J S, Masgrau R, et al. Sperm deliver a new second messenger: NAADP. Curr Biol, 2003, 13: 125-128

107 Churamani D, Carrey E A, Dickinson G D, et al. Determination of cellular nicotinic acid adenine dinucleotide phosphate (NAADP) levels. Biochem J, 2004, 380: 449-454

108 Aarhus R, Graeff R M, Dickey D M, et al. ADP-ribosyl cyclase and CD38 catalyze the synthesis of a calcium-mobilizing metabolite from NADP. J Biol Chem, 1995, 270: 30327-30333

109 Kim S Y, Cho B H, Kim U H. CD38-mediated $\mathrm{Ca}^{2+}$ signaling contributes to angiotensin II-induced activation of hepatic stellate cells: attenuation of hepatic fibrosis by CD38 ablation. J Biol Chem, 2010, 285: 576-582

110 Rah S Y, Mushtaq M, Nam T S, et al. Generation of cyclic ADP-Ribose and nicotinic acid adenine dinucleotide phosphate by CD38 for $\mathrm{Ca}^{2+}$ signaling in interleukin-8-treated lymphokineactivated killer cells. J Biol Chem, 2010, 285: 21877-21887

111 Cosker F, Cheviron N, Yamasaki M, et al. The ecto-enzyme CD38 is a NAADP synthase which couples receptor activation to $\mathrm{Ca}^{2+}$ mobilization from lysosomes in pancreatic acinar cells. J Biol Chem, 2010, 285: 38251-38259

112 Jackson D G, Bell J I. Isolation of a cDNA encoding the human CD38 (T10) molecule, a cell surface glycoprotein with an unusual discontinuous patern of expression during lymphocyte differentiation. J Immunol, 1990, 144: 2811-2815

113 Prasad G S, McRee D E, Stura E A, et al. Crystal structure of Aplysia ADP ribosyl cyclase, a homologue of the bifunctional ectozyme CD38. Nature Struct Biol, 1996, 3: 957-964

114 Munshi C, Baumann C, Levitt D, et al. The homo-dimeric form of ADP-ribosyl cyclase in solution. Biochim Biophys Acta, 1998, 1388: 428-436

115 Munshi C, Thiel D J, Mathews I I, et al. Characterization of the active site of ADP-ribosyl cyclase. J Biol Chem, 1999, 274: 30770-30777

116 Liu Q, Kriksunov I A, Graeff R, et al. Crystal structure of human CD38 extracellular domain. Structure, 2005, 13: 1331-1339

117 Liu Q, Kriksunov I A, Graeff R, et al. Structural basis for formation and hydrolysis of calcium messenger cyclic ADP-ribose by human CD38. J Biol Chem, 2007, 282: 5853-5861

118 Liu Q, Graeff R, Kriksunov I A, et al. Conformational closure of the catalytic site of human CD38 induced by calcium. Biochemistry, 2008, 47: 13966-13973

119 Munshi C, Aarhus R, Graeff R, et al. Identification of the enzymatic active site of CD38 by site-directed mutagenesis. J Biol Chem, 2000, 275: 21566-21571

120 Graeff R, Liu Q, Kriksunov I A, et al. Mechanism of cyclizing NAD to cyclic ADP-ribose by ADP-ribosyl cyclase and CD38. J Biol Chem, 2009, 284: 27629-27636

121 Graeff R, Munshi C, Aarhus R, et al. A single residue at the active site of CD38 determines its NAD cyclizing and hydrolyzing activities. J Biol Chem, 2001, 276: 12169-12173

122 Graeff R, Liu Q, Kriksunov I A, et al. Acidic residues at the active sites of CD38 and ADP-ribosyl cyclase determine NAADP synthesis and hydrolysis activities. J Biol Chem, 2006, 281: 28951-28957

123 Liu Q, Kriksunov I A, Graeff R, et al. Structural basis for the mechanistic understanding of human CD38 controlled multiple catalysis. J Biol Chem, 2006, 281: 32861-32869

124 Liu Q, Kriksunov I A, Jiang H, et al. Covalent and noncovalent intermediates of an NAD utilizing enzyme, human CD38. Chem Biol, 2008, 15: 1068-1078

125 Zhang H, Graeff R, Chen Z, et al. Dynamic conformations of the CD38-mediated NAD cyclization captured in a single crystal. J Mol Biol, 2011, 405: 1070-1078

126 Mohanty B, Serrano P, Pedrini B, et al. Comparison of NMR and crystal structures for the proteins TM1112 and TM1367. Acta Crystallogr Sect F Struct Biol Cryst Commun, 2010, 66: 1381-1392

127 Galione A, White A, Willmott N, et al. cGMP mobilizes intracellular $\mathrm{Ca}^{2+}$ in sea urchin eggs by stimulating cyclic ADP-ribose synthesis. Nature, 1993, 365: 456-459

128 Willmott N, Sethi J K, Walseth T F, et al. Nitric oxide-induced mobilization of intracellular calcium via the cyclic ADP-ribose signaling pathway. J Biol Chem, 1996, 271: 3699-705

129 Wilson H L, Galione A. Differential regulation of nicotinic acid adenine dinucleotide phosphate and cADP-ribose production by cAMP and cGMP. Biochem J, 1998, 331: 837-843

130 Graeff R M, Franco L, De Flora A, et al. Cyclic GMP-dependent and -independent effects on the synthesis of the calcium messengers cyclic ADP-ribose and nicotinic acid adenine dinucleotide phosphate. J Biol Chem, 1998, 273: 118-125

131 Reyes-Harde M, Empson R, Potter B V L, et al. Evidence of a role for cyclic ADP-ribose in long-term synaptic depression in hippocampus. Proc Natl Acad Sci USA, 1999, 96: 4061-4066

132 Shawl A I, Park K H, Kim U H. Insulin receptor signaling for the proliferation of pancreatic beta-cells: Involvement of $\mathrm{Ca}^{2+}$ second messengers, IP3, NAADP and cADPR. Islets, 2009, 1: 216-223

133 Sternfeld L, Krause E, Guse A H, et al. Hormonal control of ADP-ribosyl cyclase in pancreatic acinar cells from rat. J Biol Chem, 2003, 36: 33629-33636

134 Xie G H, Rah S Y, Kim S J, et al. ADP-ribosyl cyclase couples to cyclic AMP signaling in the cardiomyocytes. Biochem Biophys Res Commun, 2005, 330: 1290-1298

135 Bruzzone S, Moreschi I, Usai C, et al. Abscisic acid is an endogenous cytokine in human granulocytes with cyclic ADP-ribose as second messenger. Proc Natl Acad Sci USA, 2007, 104: 5759-5764

136 Magnone M, Bruzzone S, Guida L, et al. Abscisic acid released by human monocytes activates monocytes and vascular smooth muscle cell responses involved in atherogenesis. J Biol Chem, 2009, 284: 17808-17818

137 Bruzzone S, Moreschi I, Guida L, et al. Extracellular NAD ${ }^{+}$regulates intracellular calcium levels and induces activation of human granulocytes. Biochem J, 2006, 393: 697-704

138 De Flora A, Guida L, Franco L, et al. The CD38/Cyclic ADP-ribose system-A topological paradox. Int J Biochem Cell Biol, 1997, 29: 1149-1166

139 De Flora A, Zocchi E, Guida L, et al. Autocrine and paracrine calcium signaling by the CD38/NAD ${ }^{+} /$cyclic ADP-ribose system. Ann NY Acad Sci, 2004, 1028: 176-191

140 Bruzzone S, Franco L, Guida L, et al. A self-restricted CD38-connexin 43 cross-talk affects $\mathrm{NAD}^{+}$and cyclic ADP-ribose metabolism and regulates intracellular calcium in $3 \mathrm{~T} 3$ fibroblasts. $\mathrm{J}$ Biol Chem, 2001, 276: 48300-48308

141 Bruzzone S, Guida L, Zocchi E, et al. Connexin 43 hemi channels mediate $\mathrm{Ca}^{2+}$-regulated transmembrane NAD+ fluxes in intact cells. Faseb J, 2001, 15: 10-12

142 Guida L, Bruzzone S, Sturla L, et al. Equilibrative and concentrative nucleoside transporters mediate influx of extracellular cyclic ADP-Ribose into 3T3 murine fibroblasts. J Biol Chem, 2002, 277: 47097-47105

143 Guida L, Franco L, Bruzzone S, et al. Concentrative influx of functionally active cyclic ADP-ribose in dimethylsulfoxide-differen- 
tiated HL-60 cells. J Biol Chem, 2004, 279: 22066-22075

144 Yamada M, Mizuguchi M, Otsuka N, et al. Ultrastructural localization of CD38 immunoreactivity in rat brain. Brain Res, 1997, 756: $52-60$

145 Kou W, Banerjee S, Eudy J, et al. CD38 regulation in activated astrocytes: Implications for neuroinflammation and HIV-1 brain infection. J Neurosci Res, 2009, 87: 2326-2339

146 Davis L C, Morgan A J, Ruas M, et al. $\mathrm{Ca}^{2+}$ Signaling occurs via second messenger release from intraorganelle synthesis sites. Curr Biol, 2008, 18: 1612-1618

147 Adebanjo O A, Anandatheerthavarada H K, Koval A P, et al. A new function for CD38/ADP-ribosyl cyclase in nuclear $\mathrm{Ca}^{2+}$ homeostasis. Nature Cell Biol, 1999, 1: 409-414

148 Khoo K M, Han M-K, Park J B, et al. Localization of the cyclic ADP-ribose-dependent calcium signaling pathway in hepatocyte nucleus. J Biol Chem, 2000, 275: 24807-24817

149 Yalcintepe L, Albeniz I, Adin-Cinar S, et al. Nuclear CD38 in retinoic acid-induced HL-60 cells. Exper Cell Res, 2005, 303: 14-21

150 Higy M, Junne T, Spiess M. Topogenesis of membrane proteins at the endoplasmic reticulum. Biochemistry, 2004, 43: 12716-12722

151 Seppala S, Slusky J S, Lloris-Garcera P, et al. Control of membrane protein topology by a single C-terminal residue. Science, 2010, 328: 1698-1700

152 Hegde R S, Mastrianni J A, Scott M R, et al. A transmembrane form of the prion protein in neurodegenerative disease. Science, 1998, 279: 827-834

153 Hegde R S, Voigt S, Lingappa V R. Regulation of Protein topology by trans-acting factors at the endoplasmic reticulum. Mol Cell, 1998, 2: 85-91

154 Stewart R S, Harris D A. A transmembrane form of the prion protein is localized in the Golgi apparatus of neurons. J Biol Chem, 2005, 280: $15855-15864$

155 Stewart R S, Harris D A. Mutational analysis of topological determinants in prion protein $(\operatorname{PrP})$ and measurement of transmembrane and cytosolic PrP during prion infection. J Biol Chem, 2003, 278: 45960-45968

156 Cumming R C, Andon N L, Haynes P A, et al. Protein disulfide bond formation in the cytoplasm during oxidative stress. J Biol Chem, 2004, 279: 21749-21758

157 Brennan J P, Wait R, Begum S, et al. Detection and mapping of widespread intermolecular protein disulfide formation during cardiac oxidative stress using proteomics with diagonal electrophoresis. J Biol Chem, 2004, 279: 41352-41360

158 Stewart E J, Åslund F, Beckwith J. Disulfide bond formation in the Escherichia coli cytoplasm: an in vivo role reversal for the thioredoxins. EMBO J, 1998, 17: 5543-5550

159 Zhao Y J, Zhang H M, Lam C M C, et al. Cytosolic CD38 forms intact disulfides and is active in elevating intracellular cyclic ADP-ribose. J Biol Chem, 2011, 286: 22170-22177

160 Harden A, Young W J. The alcoholic ferment of yeast-juice. Proc R Soc London, 1906, 78: 369-375

161 Warburg O, Christian W. Pyridin, the hydrogen-transferring component of the fermentation enzymes (pyridine nucleotide). Biochem Z, 1936, 287: 291

Open Access This article is distributed under the terms of the Creative Commons Attribution License which permits any use, distribution, and reproduction in any medium, provided the original author(s) and source are credited. 